\title{
Pneumococcal peritonitis: Still with us and likely to increase in importance
}

\author{
Darcy C Waisman $\mathrm{BSc}^{1,2}$, Gregory J Tyrrell $\mathrm{PhD}^{3}$, James D Kellner $\mathrm{MD}^{4}$, Sipi Garg PhD ${ }^{5}$, Thomas J Marrie $\mathrm{MD}^{2}$
}

\author{
DC Waisman, GJ Tyrrell, JD Kellner, S Garg, TJ Marrie. \\ Pneumococcal peritonitis: Still with us and likely to increase in \\ importance. Can J Infect Dis Med Microbiol 2010;21(1):e23- \\ e27.
}

BACKGROUND: Pneumococcal peritonitis is uncommon and poorly understood.

METHODS: As part of a five-year study (2000 to 2004) of invasive pneumococcal disease (IPD) in Alberta, all cases of peritonitis due to Streptococcus pneumoniae were reviewed and compared with all other cases of IPD.

RESULTS: Twenty-three of 1768 (1.3\%) IPD patients were found to have peritonitis. Patients with peritonitis were more likely to have cirrhosis, hepatitis C, alcoholism and HIV/AIDS, than the remainder of the patients with IPD. The all-cause mortality did not differ between the two groups. Peritonitis was classified as primary in nine (39\%) patients, secondary in $12(52 \%)$ patients, and genitourinary in females, specifically, in two (9\%) patients. Pneumococcal serotypes causing peritonitis were under-represented in current vaccines $-17 \%$ among peritonitis patients versus $53 \%$ for the remainder of IPD patients for the 7 -valent pneumococcal conjugate vaccine, and $56 \%$ versus $86 \%$ for the 23 -valent pneumococcal polysaccharide vaccine.

CONCLUSIONS: Peritonitis represents a small subset of patients with IPD, but one that is likely to grow in importance given the increase in the number of patients with hepatitis $\mathrm{C}$ and HIV, and the reduced coverage of peritonitis serotypes in currently available vaccines.

Key Words: Mortality; Peritonitis; Pneumococcal; Serotypes; Vaccine

Dneumococcal peritonitis is a relatively uncommon mani1 festation of Streptococcus pneumoniae infection (1), but nonetheless, a potentially life-threatening one (2) that requires prompt medical attention and treatment with antibiotics and, in some cases, surgery (3).

Since the first descriptions of spontaneous bacterial peritonitis in English medical literature (in the United Kingdom in 1963 by Kerr et al [4] and in the United States in 1964 by Conn [5]), our knowledge of pneumococcal peritonitis has continued to evolve. Currently, this entity is classified into three groups: primary pneumococcal peritonitis associated with liver disease, including cirrhosis, viral hepatitis $\mathrm{B}$ or $\mathrm{C}$, chronic renal failure and continuous ambulatory peritoneal dialysis or nephrotic syndrome; pneumococcal peritonitis sometimes presenting with an apparent genitourinary focus in young females; and secondary (or tertiary) peritonitis associated with gastrointestinal disease or after intra-abdominal surgery (1).

All cases of invasive pneumococcal disease (IPD) in the province of Alberta during the five-year period from 2000 to

\section{La péritonite pneumococcique : Toujours existante et susceptible de gagner en importance}

HISTORIQUE : La péritonite pneumococcique est peu courante et mal
comprise. MÉTHODOLOGIE : Dans le cadre d'une étude de cinq ans (2000 à 2004) sur la maladie à pneumocoque envahissante (MPE) en Alberta, les auteurs ont examiné tous les cas de péritonite imputables à un Streptococcus pneumoniae et les ont comparés à tous les autres cas de MPE.

RÉSULTATS : On a déterminé que 23 des 1768 patients (1,3\%) ayant une MPE étaient atteints d'une péritonite. Ces patients étaient plus susceptibles de souffrir d'une cirrhose, d'une hépatite C, d'alcoolisme et de VIH-sida que les autres patients ayant une MPE. La mortalité toutes causes confondues ne différait pas entre les deux groupes. La péritonite était classée comme primaire chez neuf $(39 \%)$ patients, secondaire chez $12(52 \%)$ patients et génito-urinaire chez les femmes, notamment deux (9\%) patientes. Les sérotypes pneumococciques responsables de la péritonite étaient sous-représentés dans les vaccins actuels, soit $17 \%$ chez les patients atteints de péritonite par rapport à $53 \%$ des autres patients atteints d'une MPE pour le vaccin conjugué pneumococcique septavalent, et $56 \%$ par rapport à $86 \%$ pour le vaccin polysaccharidique pneumococcique 23-valent.

CONCLUSIONS : La péritonite représente un petit sous-ensemble de patients atteints d'une MPE, mais elle risque de gagner en importance étant donné l'augmentation du nombre de patients atteints d'hépatite $\mathrm{C}$ et de VIH et la couverture réduite des sérotypes de péritonite dans les vaccins actuellement offerts.

2004 were reviewed, and 23 cases of peritonitis due to $S$ pneumoniae were found. The purpose of the present paper was to discuss our experience with these cases, and illustrate how the clinical picture of pneumococcal peritonitis has changed. In addition, patients with pneumococcal peritonitis were compared with those who had other manifestations of IPD to determine the differences.

\section{METHODS}

The study period was from 2000 to 2004 and encompassed the province of Alberta (population in 2000 was 2,967,755 and in 2004 was $3,179,036)$. IPD was defined according to the Canadian national case definition: isolation of $S$ pneumoniae from a normally sterile site such as blood, cerebrospinal fluid, pleural fluid, biopsy tissue, joint aspiration, pericardial fluid or peritoneal fluid (6). In Alberta, IPD is a notifiable disease reportable to the provincial health office. This categorization of IPD in Alberta requires all clinical laboratories that identify $S$ pneumoniae from such cases to submit the pneumococcal

${ }^{1}$ University College Dublin, Dublin, Ireland; ${ }^{2}$ Department of Medicine, Faculty of Medicine and Dentistry; ${ }^{3}$ Department of Laboratory Medicine and Pathology, University of Alberta, Edmonton; ${ }^{4}$ Department of Paediatrics, University of Calgary, Calgary; ${ }^{5}$ EPICORE centre, University of Alberta, Edmonton, Alberta

Correspondence: Dr Thomas J Marrie, Department of Medicine, Faculty of Medicine, Dalhousie University, Room C205, 5849 University Avenue, Halifax, Nova Scotia B3H 4H7. Telephone 902-494-1846, fax 902-494-7119, e-mail t.marrie@dal.ca 
TABLE 1

Comparison of 23 cases of pneumococcal peritonitis with 1745 cases of nonperitonitis invasive pneumococcal disease (IPD)

\begin{tabular}{|c|c|c|c|c|}
\hline & $\begin{array}{c}\text { Overall }(n=1768), \\
n(\%)\end{array}$ & $\begin{array}{c}\text { Peritonitis }(n=23), \\
n(\%)\end{array}$ & $\begin{array}{c}\text { Other IPD (n=1745), } \\
n(\%)\end{array}$ & $\mathbf{P}$ \\
\hline Age, years (mean \pm SD) & $41.31 \pm 28.55$ & $42.33 \pm 23.21$ & $41.30 \pm 28.62$ & 0.88 \\
\hline \multicolumn{5}{|l|}{ Serotype } \\
\hline $6 \mathrm{~A}$ & $73(4.13)$ & $5(21.74)$ & $68(3.90)$ & - \\
\hline $6 B$ & $121(6.84)$ & $2(8.70)$ & $119(6.82)$ & - \\
\hline 1 & $61(3.45)$ & $1(4.35)$ & $60(3.44)$ & - \\
\hline 13 & $8(0.45)$ & $1(4.35)$ & $7(0.40)$ & - \\
\hline $15 B$ & $9(0.51)$ & $1(4.35)$ & $8(0.46)$ & - \\
\hline $17 \mathrm{~F}$ & $11(0.62)$ & $1(4.35)$ & $10(0.57)$ & - \\
\hline $19 \mathrm{~F}$ & $104(5.88)$ & $2(8.70)$ & $102(5.85)$ & - \\
\hline PCV13 & $1259(71.21)$ & $10(43.48)$ & $1249(71.58)$ & 0.003 \\
\hline PPV23 & $1520(85.97)$ & $13(56.52)$ & $1507(86.36)$ & $<0.0001$ \\
\hline Blood culture (+) & $1598(90.38)$ & $12(52.17)$ & $1586(90.89)$ & $<0.0001$ \\
\hline Peritoneal fluid $(+)$ & $11(0.62)$ & $11(47.83)$ & - & - \\
\hline Fully functional before admission & $1150(65.05)$ & $15(65.22)$ & $1135(65.04)$ & 0.88 \\
\hline Walking with assistance & $182(10.29)$ & $3(13.04)$ & $179(10.26)$ & - \\
\hline Overall mortality & $226(12.78)$ & $5(21.74)$ & $221(12.66)$ & 0.20 \\
\hline Discharged to home care & $154(8.71)$ & $5(21.74)$ & $149(8.54)$ & 0.04 \\
\hline Cancer past 5 years & $155(8.77)$ & $4(17.39)$ & $151(8.65)$ & 0.14 \\
\hline Hepatic cirrhosis & $66(3.73)$ & $9(39.13)$ & $57(3.27)$ & $<0.0001$ \\
\hline Hepatitis C & $117(6.62)$ & $5(21.74)$ & $112(6.42)$ & 0.015 \\
\hline
\end{tabular}

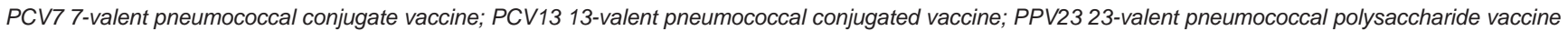

isolates to the National Centre for Streptococcus (NCS) located in Edmonton, Alberta, for capsular serotyping and antimicrobial resistance testing. To ensure that case ascertainment was as complete as possible during the study period, all reported IPD cases were identified from the NCS, the provincial health office and two active-surveillance research projects - the Community Acquired Pneumonia Study (CAPS) in Edmonton, and the Calgary S pneumoniae Epidemiology Research (CASPER) study in Calgary, Alberta. Data from these four sources were combined to form the complete data set. Cases found in more than one source were counted once only.

Data collection and definition of pneumococcal peritonitis Trained research nurses reviewed the clinical records of all patients with IPD and recorded the data using standardized case report forms. The data were entered into FileMaker Pro version 8.5 (FileMaker Inc, USA) and transferred to SPSS version 11 (SPSS Inc, USA) for analysis.

The subset of patients with pneumococcal peritonitis were defined as those with a clinical diagnosis of peritonitis (abdominal pain with guarding and tenderness to palpation), and $S$ pneumoniae isolated from the blood and/or peritoneal fluid. The records were re-reviewed by one of the authors (TJM) to ensure that the case definition was met.
Peritonitis was classified as primary; with an apparent genitourinary focus in young females; and secondary, as described by Capdevila et al (1).

Serotyping of pneumococcal isolates

Isolates received at the NCS were confirmed to be S pneumoniae using optochin susceptibility and bile solubility assays (7). Serotyping of all pneumococcal isolates was performed at the NCS by the Quellung reaction using commercial antisera obtained from the Statens Serum Institut in Copenhagen, Denmark (8). Isolates were categorized as those included in the 7-valent protein conjugate vaccine $(4,6 \mathrm{~B}, 9 \mathrm{~V}, 14,18 \mathrm{C}, 19 \mathrm{~F}, 23 \mathrm{~F})$, 7-valent protein conjugate vaccine related $(6 \mathrm{~A}, 19 \mathrm{~A})$ and those in the 23 -valent polysaccharide vaccine $(1,2,3,4,5,6 \mathrm{~B}, 7 \mathrm{~F}, 8,9 \mathrm{~N}, 9 \mathrm{~V}, 10 \mathrm{~A}, 11 \mathrm{~A}$, 12F, 13, 14, 15B, 17F, 18C, 19A, 19F, 20, 22F, 23F, 33F).

\section{Antimicrobial susceptibility assays}

Antibiotic susceptibility was determined using reference broth microdilution methods as recommended by the Clinical and Laboratory Standards Institute guidelines (9). The following antimicrobial agents were assayed: penicillin, ceftriaxone, chloramphenicol, erythromycin, clindamycin, tetracycline, trimethoprim-sulfamethoxazole, levofloxacin and vancomycin. All antimicrobial agents were purchased from Sigma-Aldrich 
TABLE 2

Clinical features and outcome of peritonitis cases $(n=23)$

\begin{tabular}{|c|c|c|c|c|c|c|c|c|}
\hline Sex & $\begin{array}{l}\text { Age, } \\
\text { years }\end{array}$ & $\begin{array}{l}\text { Culture } \\
\text { source }\end{array}$ & Comorbidity & $\begin{array}{c}\text { Altered mental } \\
\text { state at } \\
\text { presentation }\end{array}$ & Ascites & Type of peritonitis & Pneumonia & Outcome \\
\hline $\bar{F}$ & 2 & Blood & None & - & - & $\begin{array}{l}\text { Peritonitis in a young } \\
\text { female }\end{array}$ & - & - \\
\hline M & 3 & Blood & Nephrotic syndrome & - & Yes & Primary & Yes & - \\
\hline M & 4 & Blood & Nephrotic syndrome & - & Yes & Primary & - & - \\
\hline $\mathrm{F}$ & 9 & $\mathrm{PF}$ & Bladder rupture, hepatitis C & - & - & Secondary & Yes & - \\
\hline M & 27 & PF & $\begin{array}{l}\text { Small bowel obstruction, peritonitis-infected } \\
\text { appendectomy wound }\end{array}$ & - & - & Secondary & - & - \\
\hline $\mathrm{F}$ & 28 & Blood & $\begin{array}{l}\text { GI bleed, alcoholism, cirrhosis, } \\
\text { rheumatoid arthritis }\end{array}$ & - & - & Secondary & - & - \\
\hline $\mathrm{F}$ & 34 & Blood & $\begin{array}{l}\text { Kaposi's sarcoma, HIVIAIDS, cirrhosis, } \\
\text { hepatitis C }\end{array}$ & Yes & Yes & Primary & Yes & Died \\
\hline M & 35 & PF & $\begin{array}{l}\text { Pancreatitis, subrenic abscess, perforated } \\
\text { duodenum ulcer }\end{array}$ & Yes & Yes & Secondary & - & - \\
\hline $\mathrm{F}$ & 37 & Blood/PF & GI bleed, alcoholism, cirrhosis, hepatitis C & Yes & Yes & Primary & Yes & Died \\
\hline $\mathrm{F}$ & 40 & PF & Pelvic abscess & Yes & - & $\begin{array}{l}\text { Peritonitis in a young } \\
\text { woman }\end{array}$ & - & - \\
\hline $\mathrm{F}$ & 42 & Blood & $\begin{array}{l}\text { Liver failure, septic shock, alcoholism, HIVIAIDS, } \\
\text { GI bleed, hepatitis C }\end{array}$ & Yes & - & Secondary & - & - \\
\hline M & 43 & Blood & $\begin{array}{l}\text { Pancreatitis, pseudocyst, alcoholism, } \\
\text { cirrhosis of the liver }\end{array}$ & Yes & - & Secondary & Yes & - \\
\hline $\mathrm{F}$ & 47 & Blood & $\begin{array}{l}\text { Alcoholism, HIVIAIDs, GI bleed, pancreatitis, } \\
\text { hepatitis C }\end{array}$ & - & - & Secondary & Yes & - \\
\hline M & 51 & Blood & Alcoholism, cirrhosis & - & Yes & Primary & Yes & - \\
\hline M & 53 & PF & Incarcerated incisional hernia & - & - & Secondary & - & - \\
\hline $\mathrm{F}$ & 55 & Blood & Cirrhosis & - & Yes & Primary & - & Died \\
\hline M & 56 & PF & Pancreatic cancer, metastic liver disease & Yes & - & Secondary & - & Died \\
\hline $\mathrm{F}$ & 57 & Blood & GI bleed, cirrhosis & Yes & - & Secondary & - & - \\
\hline $\mathrm{F}$ & 58 & PF & Cirrhosis, alcoholism, hepatitis C & Yes & - & Primary & - & Died \\
\hline $\mathrm{F}$ & 61 & Blood & Sepsis, cirrhosis & - & Yes & Primary & Yes & - \\
\hline M & 63 & PF & Perforated duodenum, inflammatory bowel disease & - & - & Secondary & Yes & - \\
\hline $\mathrm{F}$ & 82 & PF/blood & SPB, cirrhosis, chronic renal failure & - & Yes & Primary & - & - \\
\hline $\mathrm{F}$ & 86 & $\mathrm{PF}$ & Pancreatic cancer & Yes & - & Secondary & - & - \\
\hline
\end{tabular}

Data from SPSS version 11.0 (SPSS Inc, USA). F Female; GI Gastrointestinal; M Male; PF Peritoneal fluid; SPB Spontaneous bacterial peritonitis

Canada Ltd. The minimum inhibitory concentrations used to interpret susceptibility for $S$ pneumoniae were those that were current at the time that the assay was performed (9).

\section{RESULTS}

There were 1768 IPD patients during the period under surveillance, of which $23(1.3 \%)$ had peritonitis. Table 1 provides a comparison of patients with peritonitis with those who had other manifestations of IPD. The analysis showed an over-representation of Aboriginal persons and, as expected, 39\% of patients with peritonitis had cirrhosis compared with only $3 \%$ of the remaining IPD patients. Hepatitis $\mathrm{C}$ was the major cause of liver disease among the patients with peritonitis (22\%) compared with the remaining IPD patients $(6 \%)$, and there was a high rate of admission to surgery at $22 \%$ versus $2 \%$ for the remainder of the cases. Also, patients with HIV/AIDS were over-represented among the patients with peritonitis compared with the remaining IPD patients ( $13 \%$ versus $3 \%)$. The all-cause mortality rate of $25 \%$ among the peritonitis patients was not significantly higher than that of $13 \%$ for the remainder of the IPD patients.

All vaccine serotypes had a much lower frequency in the peritonitis patients versus those with other manifestations of IPD, as shown in Table 1.
Table 2 details the clinical features for each patient. Only five isolates were from the peritoneal fluid. which in part, was due to the presence of ascites in only nine patients. While there were six patients with nephrotic syndrome in the entire study, only two had peritonitis.

The mean $( \pm$ SD) length of stay of $13 \pm 12.8$ days for patients with peritonitis was not significantly longer than the $8 \pm 25$ days for the other patients.

Fifteen isolates were available for susceptibility testing (eight were not submitted to our laboratory). Ten of the isolates were from blood, and five were from peritoneal fluid. All isolates assayed were susceptible to penicillin, ceftriaxone, chloramphenicol, tetracycline, vancomycin, clindamycin and levofloxacin. Three (20\%) were resistant to erythromycin and two were of intermediate susceptibility to trimethoprim-sulfamethoxazole. In comparison, data from the nonperitonitis IPD patients revealed that $9.7 \%$ of the isolates were resistant to penicillin, $8.3 \%$ to erythromycin and $18.8 \%$ to trimethoprimsulfamethoxazole.

Table 2 shows selected data for all 23 patients. Four were children, two of whom had nephrotic syndrome as a predisposing cause. What is evident from the table is the complexity of the patients. Only the two patients classified as 
'peritonitis in a young female' had no comorbidities. Nine patients had ascites and nine had pneumonia. Seven patients suffered from alcoholism. Pancreatic disease was also prominent in two patients with pancreatic cancer, and three with pancreatitis. Ten patients had altered mental status; four patients were afebrile. Nine patients had primary peritonitis, 12 had secondary peritonitis and two were classified as peritonitis in a young female.

\section{DISCUSSION}

Just over $1 \%$ of all our patients with IPD had pneumococcal peritonitis. In a study of the epidemiology of IPD in the United States, Robinson et al (10) reported 15,860 cases that occurred between 1995 and 1998. They did not indicate the number of cases of peritonitis in their study, nor if any occurred. It is noteworthy that in our overall study population, $15 \%$ of patients had alcoholism and $3.7 \%$ had cirrhosis.

When categorized according to the schema proposed by Capdevila et al (1), $52 \%$ of our patients had secondary peritonitis, 39\% had primary peritonitis and $9 \%$ were young females who had peritonitis presumably due to an ascending infection through the genital tract (11). Hemsley and Eykyn (11), in a review of the literature from 1995 to 1998, noted only 27 cases of pneumococcal peritonitis in women who were otherwise healthy. In this group, 13 of 17 (76\%) patients who had blood cultures performed had S pneumoniae bacteremia. Seven had pelvic inflammatory disease, six had appendicitis, six had intrauterine contraceptive devices and two occurred postpartum. Patient 10 had a pelvic abscess and no other comorbidities. Patient 1 was a two-year-old girl who fit the original description of primary pneumococcal peritonitis.

Nielsen et al (12) identified 18 cases of pneumococcal peritonitis over five years in two Danish counties. They proposed a new classification of pneumococcal peritonitis: children $-33 \%$ of their patients fit this category; women of child-bearing age $44 \%$; and older patients - 22\%. Applying this classification to our patients, $17 \%$ were children, $22 \%$ were women of childbearing age and $61 \%$ were older patients.

Three $(13 \%)$ of the patients in our study had HIV/AIDS, all of whom were also hepatitis $\mathrm{C}$ positive. Because HIV/AIDS has become a chronic disease with the advent of effective antiretroviral therapy, pneumococcal peritonitis will be an increasingly frequent complication of HIV/AIDS further complicated by hepatitis $C(13,14)$. Indeed, cirrhotic patients with HIV and spontaneous bacterial peritonitis have a higher rate of $S$ pneumoniae infection as the etiological agent of the peritonitis compared with non-HIV-infected patients (14). The long-term prognosis for HIV/AIDS patients with pneumococcal peritonitis is poor (14).

Spontaneous bacterial peritonitis is also known to be a severe complication of nephrotic syndrome, and yet one that despite being characteristic in children, tends to be rare in adults (15-17). S pneumoniae is the most common causative agent of spontaneous bacterial peritonitis in patients with nephrotic syndrome (15).

In our study, one patient had rheumatoid arthritis and one patient had lupus, an autoimmune disorder that has been diagnosed in increased incidence in patients with pneumococcal peritonitis (18). Our patient with rheumatoid arthritis also had alcoholism and cirrhosis.
Seven (30\%) of our patients had cirrhosis, pneumonia and alcoholism. In a cirrhotic rat model of pneumococcal pneumonia, early and late defects in killing S pneumoniae were identified (19). It is well known that alcoholism is a risk factor for acquisition of pneumonia and for severity of pneumonia (20-22). Thus, there is double jeopardy for some of these patients. In all likelihood, peritonitis results from the hematogenous spread of $S$ pneumoniae in this subset of patients (1).

Some cases of pneumococcal peritonitis can be nosocomial and can be precipitated by gastrointestinal bleeding (23). Five of our patients had gastrointestinal bleeding.

The pneumococcal serotypes that caused peritonitis in our patients are under-represented in all currently marketed vaccines for $S$ pneumoniae, indicating that such vaccines are unlikely to eliminate pneumococcal peritonitis.

While the isolates that were available for antimicrobial susceptibility testing from the peritonitis patients were all susceptible to penicillin, the missing isolates limit the conclusion that we can draw from this observation.

We conclude that pneumococcal peritonitis is a small, but distinct subset of patients with IPD, and one that is likely to grow in importance given the increase in the number of patients with hepatitis $\mathrm{C}$ and HIV.

ACKNOWLEDGEMENTS: The authors thank the staff of the Acute Diagnostic Microbiology Laboratories in Alberta who submitted isolates from IPD cases to the National Centre for Streptococcus, Edmonton, Alberta. They acknowledge the contributions of Carol Mangan RN BScN, and the Data Collection Team who include Anne Witschen RN, Lynne Korobanik RN, Freda Anderson RN, Loy Bacon RN, Shannon Pyra RN, Janine Schouten BSc, Ambreen Mithani (nursing student) and Natalie Chui (University of Alberta [Edmonton, Alberta] student). The authors also thank Linda Hastie RN, the study research coordinator; Stephanie Hui BSc, research assistant; Janice Pitchko BSc MSc, research epidemiologist for designing and maintaining the study databases; and Heather Mangan BSc for her assistance with the database.

CONFLICTS OF INTEREST: Drs Tyrrell, Kellner and Marrie received a grant-in-aid from Wyeth $\{$ Pfizer Inc, USA $\}$ for the present study. In addition, they have served on the advisory board relating to pneumococcal vaccines for Wyeth.

\section{REFERENCES}

1. Capdevila O, Pallares R, Grau I, et al. Pneumococcal peritonitis in adult patients: Report of 64 cases with special reference to emergence of antibiotic resistance. Arch Intern Med 2001;161:1742-8.

2. Mowat C, Stanley AJ. Review article: Spontaneous bacterial peritonitis - diagnosis, treatment and prevention. Aliment Pharmacol Ther 2001;15:1851-9.

3. Garcia-Tsao G. Milestones in liver disease. Spontaneous bacterial peritonitis: A historical perpective. J Hepatol 2004;41:522-7.

4. Kerr DNS, Pearson DT, Read AE. Infection of ascetic fluid in patients with hepatic cirrhosis. Gut 1963;4:394-8.

5. Conn HO. Spontaneous peritonitis and bacteremia in Laennec's cirrhosis caused by enteric organisms. A relatively common but rarely recognized syndrome. Ann Intern Med 1964;60:568-80.

6. Canada Communicable Disease Report. Case definitions for diseases under national surveillance. Health Canada 2000;26:S3:51.

7. RR Facklam, Washington, JA. Streptococcus and related catalasenegative gram-positive cocci. In: A Balows, WJ Hausler Jr, KL Herrmann, HD Isenberg, HJ Shadomy, eds. Manual of Clinical Microbiology, 5th edn. Washington, DC: American Society for Microbiology, 1991:238-57. 
8. Lund R, Henrichsen J. Laboratory diagnosis, serology and epidemiology of Streptococcus penumoniae. In: Bergan T, Norris JR, eds. Methods in Microbiology, vol.12. New York, NY: Academic Press Inc, 1978:241-62.

9. Clinical and Laboratory Standards Institute. Performance standard for antimicrobial susceptibility testing Document M100-S15. Wayne, PA: CLSI, 2005.

10. Robinson KA, Baughman W, Rothrock G, et al; the Active Bacterial Core Surveillance (ABCs)/Emerging Infections Program Network. Epidemiology of invasive Streptococcus pneumoniae infections in the United States, 1995-1998: Opportunities for prevention in the conjugate vaccine era. JAMA 2001;285:1729-35.

11. Hemsley C, Eykyn SJ. Pneumococcal peritonitis in previously healthy adults: Case report and review. Clin Infect Dis 1998;2:376-9.

12. Nielsen KR, Ejlertsen T, El-Batran S, Prag J. A five-year survey of pneumococcal peritonitis in two Danish counties - incidence, diagnosis and clinical entities. Clin Microbiol Infect Dis 2003;9:738-40.

13. Alifrangis $C$, Thompson $O$, Thwaites G, Churchill D. Primary pneumococcal peritonitis as a presenting feature of HIV infection. Int J STD AIDS 2006;11:779-80.

14. Shaw E, Castellote J, Santin M, et al. Clinical features and outcome of spontaneous bacterial peritonitis in HIV-infected cirrhotic patients: A case-control study. Euro J Clin Microbiol Infect Dis 2006;5:291-8.

15. Krensky AM, Ingelfinger JR, Grupe WE. Peritonitis in childhood nephrotic syndrome: 1970-1980. Am J Dis Child 1982;8:732-6.
16. Ruiz S, Soto S, Rodado R, Alcaraz F, López Guillén E. Spontaneous bacterial peritonitis as form of presentation of idiophatic nephrotic syndrome in a black adult. Ann Med Inter 2007;9:442-4

17. Lasry F, Badre A, Naim A, Oumlil M, Khalifa HH. Primary peritonitis in children with nephrotic syndrome. Néphrologie thérapeutique 2005;5:311-4.

18. Conn HO. Spontaneous bacterial peritonitis: Variant syndromes. South Med J 1987;11:1343-6.

19. Propst-Graham KL, Preheim LC, Vander Top EA, Snitily MU, Gentry-Nielsen MJ. Cirrhosis induced defects in innate pulmonary defenses against Streptococcus pneumoniae. BMC Microbiology 2007;7:94.

20. Fernandez-Sola J, Junque A, Estruch R, Monforte R, Torres A, Urbano-Marquez A. High alcohol intake as a risk and prognostic factor for community-acquired pneumonia. Arch Intern Med 1995;155:1649-54.

21. Fine MJ, Smith MA, Carson CA, et al. Prognosis and outcomes of patients with community-acquired pneumonia. A meta-analysis. JAMA 1996:275;134-41.

22. Saitz R, Ghali WA, Moskowitz MA. The impact of alcohol-related diagnoses on pneumonia outcomes. Arch Intern Med 1997; 157:1446-52.

23. Ruynon BA. Early events in spontaneous bacterial peritonitis. Gut 2004;53:782-4. 


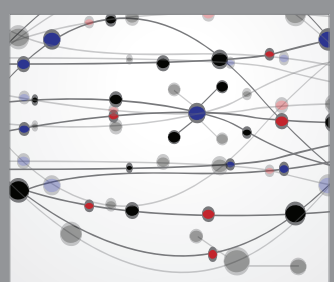

The Scientific World Journal
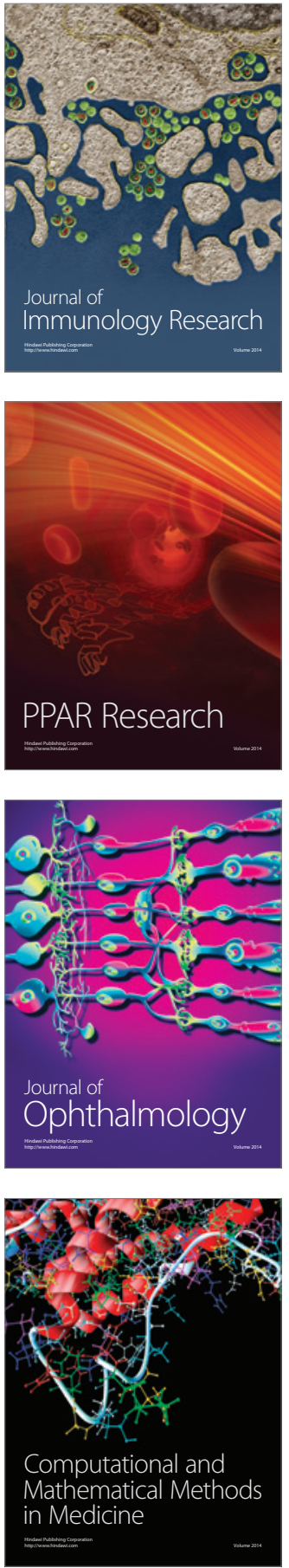

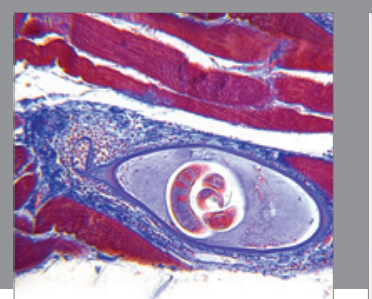

Gastroenterology Research and Practice

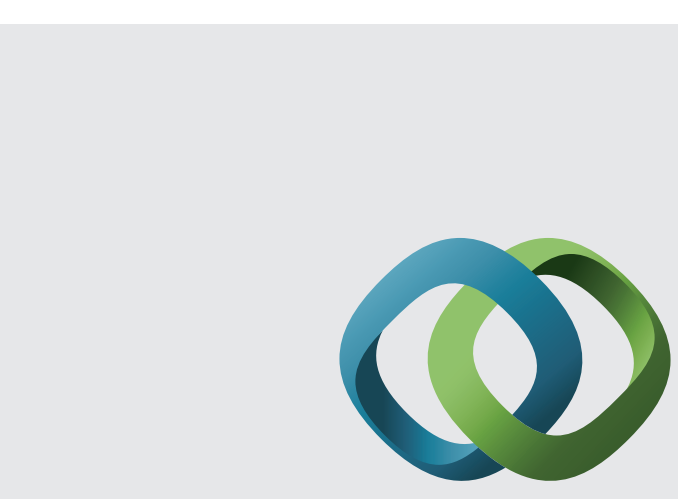

\section{Hindawi}

Submit your manuscripts at

http://www.hindawi.com
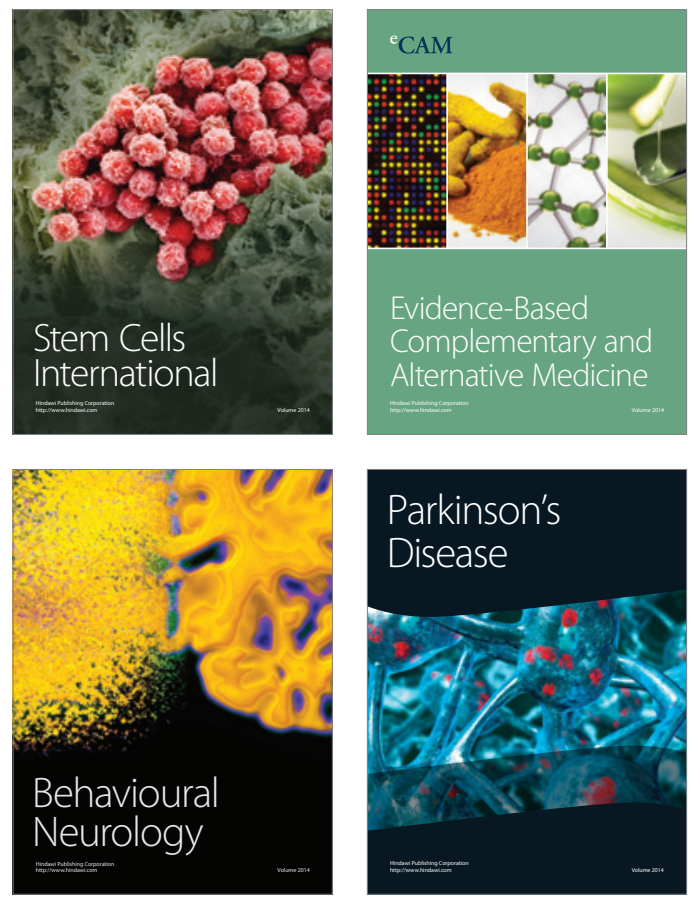
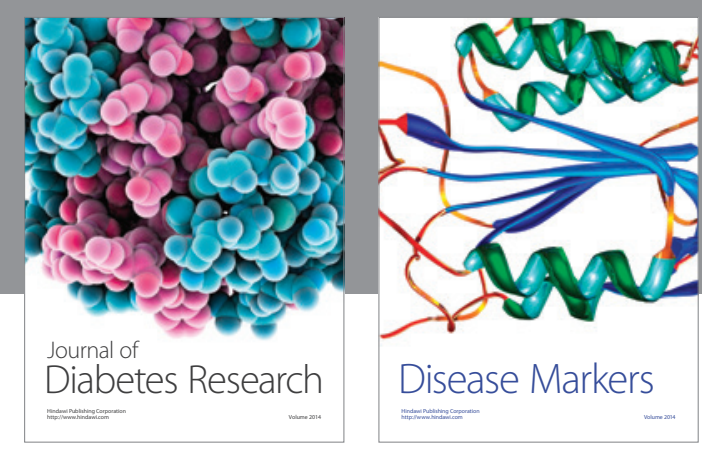

Disease Markers
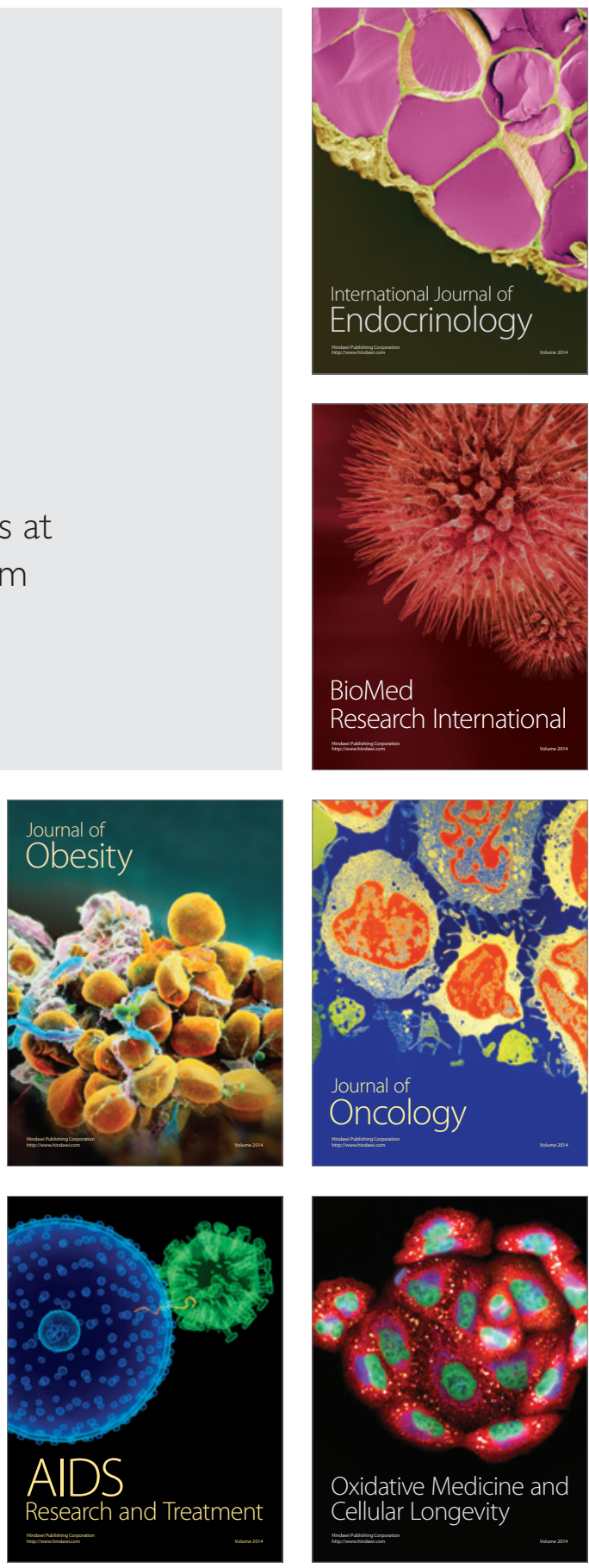